\title{
Development of the Nurses' Occupational Stressor Scale
}

\author{
Yi-Chuan Chen ${ }^{1}{ }^{\circledR}$, Yue-Liang Leon Guo ${ }^{2,3}{ }^{10}$, Li-Chan Lin ${ }^{4}$, Yu-Ju Lee ${ }^{1}$, Pei-Yi Hu ${ }^{5}$, \\ Jiune-Jye Ho ${ }^{5}$ and Judith Shu-Chu Shiao ${ }^{1,6,7, * \text { (i) }}$ \\ 1 School of Nursing, College of Medicine, National Taiwan University (NTU), No. 1, Ren-Ai Rd. Sec. 1, \\ Taipei 10051, Taiwan; d05426004@ntu.edu.tw (Y.-C.C.); r00426019@ntu.edu.tw (Y.-J.L.) \\ 2 Department of Environmental and Occupational Medicine, College of Medicine, \\ National Taiwan University (NTU), No. 1, Ren-Ai Rd. Sec. 1, Taipei 10051, Taiwan; leonguo@ntu.edu.tw \\ 3 Department of Environmental and Occupational Medicine, National Taiwan University Hospital (NTUH), \\ No. 7, Chung-Shan South Rd., Taipei 10002, Taiwan \\ 4 Institute of Clinical Nursing, National Yang-Ming University, No. 155, Sec. 2, Linong Street, \\ Taipei 11221, Taiwan; lichan@ym.edu.tw \\ 5 Institute of Labor, Occupational Safety and Health (ILOSH), Ministry of Labor, No. 99, Lane 407, \\ Hengke Rd., New Taipei City 22143, Taiwan; peiyi@mail.ilosh.gov.tw (P.-Y.H.); hjj@mail.ilosh.gov.tw (J.-J.H.) \\ 6 Department of Nursing, National Taiwan University Hospital (NTUH), No. 7, Chung-Shan South Rd., \\ Taipei 10002, Taiwan \\ 7 Occupational Health Nursing and Education Association of Taiwan (OHNEAT), No. 1, Ren-Ai Rd. Sec. 1, \\ Taipei 10051, Taiwan \\ * Correspondence: scshiao@ntu.edu.tw; Tel.: +886-2-23933353
}

Received: 27 December 2019; Accepted: 17 January 2020; Published: 19 January 2020

check for updates

\begin{abstract}
Although nurses work in stressful environments, stressors in such environments have yet to be clearly assessed. This study aimed to develop a Nurses' Occupational Stressor Scale (NOSS) with high reliability and validity. Candidate questions for the NOSS were generated by expert consensus following focus group feedback, and were used to survey in 2013. A shorter version was then developed after examination for validity and reproducibility in 2014. The accuracy of the short version of the NOSS for predicting nurses' stress levels was evaluated based on receiver operating characteristic curves to compare existing instruments for measuring stress outcomes, namely personal burnout, client-related burnout, job dissatisfaction, and intention to leave. Examination for validity and reproducibility yielded a shorter version of NOSS with only 21 items was considered sufficient for measuring stressors in nurses' work environments. Nine subscales were included: (1) work demands, (2) work-family conflict, (3) insufficient support from coworkers or caregivers, (4) workplace violence and bullying, (5) organizational issues, (6) occupational hazards, (7) difficulty taking leave, (8) powerlessness, and (9) unmet basic physiological needs. The 21-item NOSS proved to have high concurrent and construct validity. The correlation coefficients of the subscales for test-retest reliability ranged from 0.71 to 0.83 . The internal consistency (Cronbach's $\alpha$ ) coefficients ranged from 0.35 to 0.77 . The NOSS exhibited accurate prediction of personal burnout, client-related burnout, job dissatisfaction, and intention to leave.
\end{abstract}

Keywords: nurse; occupational stressor; scale development; stressor scale; work environment

\section{Introduction}

As highlighted by the International Labour Organization [1], occupational stress is an increasingly global phenomenon which affects workers in all workplaces and countries. Nurses are known to have high work demands, high occupational stress, high rates of burnout [2-4], low job satisfaction [5], 
to experience workplace bulling [6], and may have mental health problems [7]. Job stress and burnout result from the cumulative effects of stressors in nursing work, and may consequently influence patient outcomes [8-10] and nurses' intention to leave their jobs [11,12]. In accordance with the statistics of Taiwanese National Union of Nurses Associations (TUNA), presently only about $60 \%$ of licensed nurses in Taiwan practice [13]. However, Singapore and Australia have around $86.1 \%$ and $98.5 \%$ in active practice, respectively $[14,15]$. TUNA found $57.28 \%$ nurses had intention to leave nursing profession, and the three major reasons were about "salary and bonus", "heavy workload" and "work-life imbalance". Ref. [16] In the study of 10 European countries [17] showed 27.1\% nurses considered to leave the workplace, and their perceptions of nursing practice environment was an important factor of retention.

In addition to applying stress management interventions to reduce stress [18], as recommended by Happell et al. [19], an initial step toward reducing occupational stress is to understand the stressors present in nurses' work environments as well as the methods through which these stressors may be eliminated. Not only qualitative researches have been performed to look for nursing stressors $[19,20]$, but several self-report scales have been developed to measure nursing stress indicators in hospital environment, such as Expanded Nursing Stress Scale (ENSS) [21], and Practice Environment Scale of the Nursing Work Index [22]. However, stressors vary widely in different cultures and are highly influenced by health care systems. Examples of variations include those in frequencies of on-call duty, patient-to-nurse ratios, reliance on patients' families for daily partial care, regulated break times, and monetary compensation for overtime work. Additionally, although scales for measuring nursing stressors have been developed, measurements of psychological stress among nurses, including burnout, job dissatisfaction, and intention to leave, are rarely reported. The study developed a Nurses' Occupational Stressor Scale (NOSS) to identify comprehensive nursing stressors. The scale was evaluated for validity and reliability and to examine relationships among stress indicators.

\section{Materials and Methods}

\subsection{Study Design}

Two cross-sectional studies were conducted to develop an instrument to measure nurses' occupational stressors. This study was divided into three phases: (1) generation and pilot testing of candidate questions, (2) condensation of the scale according to validity and reproducibility, and (3) examination of accuracy of the condensed NOSS for predicting stress outcomes.

\subsection{Participants and Ethical Considerations}

In 2013, candidate questions for the NOSS were pilot tested on nurses who worked in hospitals with "excellent" ratings under the New Hospital Accreditation of 2012 in Taiwan. The condensed NOSS was tested in 2014. Participants were recruited from the population based on conformity and excellence under the New Hospital Accreditation between 2010 and 2013. The research protocols were approved by Research Ethics Committee of National Taiwan University Hospital with the approval numbers of 20130807RINC and 201407075RINA. Exemption of written consent was approved, and returned questionnaires were regarded as nurses' willingness to participate in the study. No ethical issues occurred during the study period.

\subsection{Data Collection}

Stratified random sampling for the questionnaire surveys in 2013 and 2014 was conducted. Electable hospitals were sampled in proportion by hierarchy. The hospital managers were invited to approve the study via phone call. Nurses were recruited from multiple wards, namely the internal medicine ward, surgical ward, maternity and pediatric ward, intensive care unit, operating room, emergency department, psychiatric department, and outpatient department. The questionnaires 
were mailed to the participating hospitals and delivered to nurses. All returned questionnaires were previewed by the researchers and then recorded through optical mark reading.

The questionnaires were self-administered. The participants' demographic characteristics, work environment traits, levels of personal burnout, client-related burnout, job satisfaction, and intentions to leave were inquired.

\subsubsection{Personal Burnout and Client-Related Burnout}

A Chinese version of the Copenhagen Burnout Inventory (C-CBI) was developed with high internal consistency, constructive validity, and criterion-related validity [23]. Personal burnout and client-related burnout are two subscales in the C-CBI, containing five and six items, respectively, to assess the frequencies of specific scenarios within the preceding week on a 5-point Likert scale (0 to 4 representing "never" to "always"). Following Chin et al. [24], the cut-off point for nurses in the high burnout group was set as the 90th percentile.

\subsubsection{Job Dissatisfaction and Intention to Leave}

Job dissatisfaction was assessed by the answer "somewhat unsatisfied" or "very unsatisfied" to the question, "Generally speaking, are you satisfied with your job?" Intention to leave a nursing job was assessed by the following three items: (1) Answering "unlikely" or "uncertain" to the question, "Do you intend to remain in your job for at least 2 more years?" (2) Obtaining a score of 7 or higher on the item, "Please rate your intention to leave on a scale of 0 to 10 , with 0 being no intention to leave and 10 being highly considering leaving." (3) Answering "once a month" or "more frequently" to the question, "How often do you think about leaving your job?"

\subsection{Data Analysis}

Data analysis was performed using JMP statistical software version 10.0 (SAS Institute, Cary, NC, USA). Descriptive statistics were calculated to summarize demographic characteristics. Test-retest reliability and internal consistency were examined by analyzing test-retest correlations and Cronbach's $\alpha$ scores. Content validity was assessed by experts. Construct validity was calculated through common factor analysis. The suitability of factor analysis was inspected using the Kaiser-Meyer-Olkin (KMO) test [25] and Bartlett's test of sphericity [26]. For all analyses, $p<0.05$ was considered statistically significant.

\section{Results}

\subsection{Phase 1: Generation and Pilot Testing of Candidate Questions}

\subsubsection{Methods of Constructing Questions}

The procedure for developing the NOSS is described sequentially as follows: information collection, content confirmation, format design, pretesting, panel discussion, expert validation, pilot study, and content determination.

After the literature review, the content of the NOSS was constructed according to research goals, and by referring to the questionnaire titled "survey of perceptions of safety and health in the work environment in 2013 Taiwan" [27] and the work-family conflict scale [28]. The researchers had the pretest to find unsuitable wordings and expert panel discussions for suggestions and clarification. The expert panel was composed of three professionals in the fields of nursing, psychiatry, and occupational medicine and six nurses from primary, secondary, and tertiary hospitals.

\subsubsection{Content Validity Index}

Expert validity was assessed after revision of the panel discussion. The experts were the aforementioned three professionals on the panel. NOSS items were scored on a Likert-type scale ( 1 and 2: 
modification required; 3: related; 4: strongly related). After alteration or deletion of inadequate items (scores lower than or equal to 2), the content validity index of the NOSS was 0.81 .

\subsubsection{Phase 1 Questionnaire Survey}

A total of 72 hospitals rated "excellent" under the 2012 Hospital Accreditation were our target hospitals. Of these 72 hospitals, 13 were tertiary hospitals, 41 were secondary hospitals, and 18 were primary hospitals. In 2013, Stratified random sampling and questionnaire survey of 7 tertiary, 10 secondary, and 2 primary hospitals was conducted. A total of 2956 questionnaires were issued and 2796 were returned. After exclusion of men, nurse managers, nurse practitioners, and incomplete questionnaires, 1781 questionnaires were deemed eligible for analysis. The effective response rate was $60.3 \%$.

The participants' demographic characteristics are summarized in Table 1; their mean age was 30.3 years, most were single (64.3\%), and most had an educational level of college or above $(63.1 \%)$. The average total working tenure was 8.6 years.

Table 1. Participant characteristics.

\begin{tabular}{|c|c|c|c|c|c|c|c|c|}
\hline \multirow{2}{*}{ Variable } & \multicolumn{4}{|c|}{ Eligible Participants in 1st Year $(N=1781)$} & \multicolumn{4}{|c|}{ Eligible Participants in 2nd Year $(N=2655)$} \\
\hline & $n$ & $\%$ & Mean & SD & $n$ & $\%$ & Mean & SD \\
\hline Age (years) & & & 30.3 & 6.6 & & & 32.5 & 7.3 \\
\hline $31-40$ & 619 & 34.8 & & & 1097 & 41.3 & & \\
\hline$\geq 40$ & 135 & 7.6 & & & 365 & 13.7 & & \\
\hline Missing & 5 & 0.3 & & & 41 & 1.5 & & \\
\hline Single & 1145 & 64.3 & & & 1439 & 54.2 & & \\
\hline Married & 606 & 34.0 & & & 1145 & 43.1 & & \\
\hline Divorce or widow & 27 & 1.5 & & & 53 & 2.0 & & \\
\hline Missing & 3 & 0.2 & & & 18 & 0.7 & & \\
\hline \multicolumn{9}{|l|}{ Educational level } \\
\hline Missing & 3 & 0.2 & & & 10 & 0.4 & & \\
\hline Total work tenure (years) & & & 8.6 & 6.8 & & & 10.1 & 7.3 \\
\hline$<5$ & 729 & 40.9 & & & 877 & 33.0 & & \\
\hline $5-10$ & 508 & 28.5 & & & 694 & 26.1 & & \\
\hline $11-15$ & 259 & 14.5 & & & 516 & 19.4 & & \\
\hline $16-20$ & 183 & 10.3 & & & 310 & 11.7 & & \\
\hline$\geq 20$ & 101 & 5.7 & & & 236 & 8.9 & & \\
\hline Missing & 1 & 0.1 & & & 22 & 0.8 & & \\
\hline Working hours/day & & & 9.3 & 1.1 & & & 9.2 & 1.2 \\
\hline Working hours/week & & & 49.9 & 8.1 & & & 47.8 & 7.7 \\
\hline Sleeping hours/day & & & 6.8 & 1.3 & & & 6.8 & 1.2 \\
\hline Had intention to leave & 255 & 15.5 & & & 255 & 10.4 & & \\
\hline
\end{tabular}

The internal consistency scores assessed by Cronbach's $\alpha$ were 0.92 for personal burnout and 0.90 for client-related burnout. The mean scores for personal burnout and client-related burnout were 63.9 and 47.9 , respectively. Of the participants, $15.5 \%$ harbored intentions to leave their jobs. 


\subsubsection{Construct Validity}

The KMO score (0.93) and Bartlett scores (chi-square statistic $=51,378.93$; degrees of freedom $=990$; $p<0.001)$ indicated that factor analysis may be practical. Common factor analysis was performed to assess the construct validity of the NOSS, resulting in 10 factors with eigenvalues greater than 1.0 (Table 2). Relying on the assumption that the dimensions of the scale were correlated or uncorrelated, we implemented Varimax (orthogonal rotation) and Promax (oblique rotation) both. The outcomes showed that Varimax and Promax grouped the same items into 10 factors. The cumulative variability of these extracted 10 factors explained by varimax was $51.8 \%$.

Table 2. Factor loadings for items loaded on 10 factors of the 43-item Nurses' Occupational Stressor Scale (NOSS) through varimax rotation.

\begin{tabular}{|c|c|}
\hline Subscales and Component Items & Factor Loading \\
\hline \multicolumn{2}{|l|}{ 1. Work Demands } \\
\hline $\begin{array}{l}\text { I am worried about receiving complaints from patients or their relatives for not meeting } \\
\text { their demands. }\end{array}$ & 0.68 \\
\hline I have to bear the negative sentiment of patients or their relatives. & 0.76 \\
\hline I do not have sufficient time to meet patients' and their relatives' demands. & 0.74 \\
\hline I am unsure of the extent of patients' conditions or treatments that I should reveal to them. & 0.59 \\
\hline Excessive duties in the workplace prevent me from attending to patients. & 0.61 \\
\hline I have to maintain professional units other than my own. & 0.49 \\
\hline \multicolumn{2}{|l|}{ 2. Work-Family Conflict } \\
\hline The burden of work affects my domestic life. & 0.75 \\
\hline $\begin{array}{l}\text { The amount of time my job occupies makes it difficult for me to fulfill } \\
\text { family responsibilities. }\end{array}$ & 0.83 \\
\hline $\begin{array}{l}\text { The burden of work makes it difficult for me to undertake my personal chores and/or } \\
\text { engage in hobbies. }\end{array}$ & 0.83 \\
\hline My job produces strain that makes it difficult for me to fulfill my family duties. & 0.83 \\
\hline $\begin{array}{l}\text { I have to adapt my schedule for family activities/outings to accommodate } \\
\text { my work responsibilities. }\end{array}$ & 0.74 \\
\hline \multicolumn{2}{|l|}{ 3. Insufficient Support from Coworkers or Caregivers } \\
\hline The professional evaluation of care of mine is opposite to that of the doctors. & 0.62 \\
\hline Doctors' temperamental nature agitates me. & 0.56 \\
\hline $\begin{array}{l}\text { I cannot instantaneously obtain patient-related information because of inadequate } \\
\text { communication within the team. }\end{array}$ & 0.68 \\
\hline Team members do not appear to help in a timely manner under urgent circumstances. & 0.65 \\
\hline Lack of support from the team affects patients' trust in me. & 0.63 \\
\hline \multicolumn{2}{|l|}{ 4. Workplace Violence and Bullying } \\
\hline Verbal abuse such as insults and sarcastic comments. & 0.66 \\
\hline Psychological abuse such as threats, discrimination, bullying, and harassment. & 0.83 \\
\hline Physical abuse such as hitting, kicking, pushing, pinching, pulling, and dragging. & 0.71 \\
\hline Sexual harassment such as inappropriate implications and behaviors. & 0.68 \\
\hline \multicolumn{2}{|l|}{ 5. Organizational Issues } \\
\hline The on-call system affects my life. & 0.66 \\
\hline My working hours include on-call hours. & -0.48 \\
\hline
\end{tabular}


Table 2. Cont.

\begin{tabular}{|c|c|}
\hline Subscales and Component Items & Factor Loading \\
\hline \multicolumn{2}{|l|}{ 5. Organizational Issues } \\
\hline I was informed of a change to my schedule at less than 24 hours' notice. & 0.54 \\
\hline The organization usually remunerates my overtime work at a low rate of pay. & 0.40 \\
\hline Not achieving a promotion (e.g., level 1 or 2 ) within the expected period affects my income. & 0.45 \\
\hline \multicolumn{2}{|l|}{ 6. Occupational Hazards } \\
\hline Exposure to chemicals such as chemotherapy drugs, alcohol, and Cidex. & 0.63 \\
\hline Exposure to radiation or strong light such as X-ray, ultraviolet light, and lasers. & 0.67 \\
\hline $\begin{array}{l}\text { I feel stressed considering that my patients might be have contagious diseases such as } \\
\text { SARS or AIDS }{ }^{\text {. }} \text {. }\end{array}$ & 0.38 \\
\hline Transporting patients or equipment. & 0.61 \\
\hline The workplace offers sufficient protective equipment such as masks and gowns. & -0.35 \\
\hline \multicolumn{2}{|l|}{ 7. Difficulty Taking Leave } \\
\hline $\begin{array}{l}\text { The level of difficulty in asking for leaves for household emergencies is__ } \\
(0 \%=\text { very difficult, } 100 \%=\text { very smooth })^{b} \text {. }\end{array}$ & 0.87 \\
\hline $\begin{array}{l}\text { The level of difficulty in excusing myself for feeling strong discomfort is___ } \% \\
(0 \%=\text { very difficult, } 100 \%=\text { very smooth })^{b} \text {. }\end{array}$ & 0.80 \\
\hline \multicolumn{2}{|l|}{ 8. Powerlessness } \\
\hline Patients' conditions do not improve. & 0.66 \\
\hline Encountering the death of a patient. & 0.70 \\
\hline I have insufficient time to offer mental health care to patients during working hours. & 0.45 \\
\hline \multicolumn{2}{|l|}{ 9. Interpersonal Relationships } \\
\hline Relationships among colleagues within the unit are generally good. & -0.34 \\
\hline I should teach student nurses and newcomers while caring for patients. & 0.55 \\
\hline I worry that my colleagues' incompetence will affect patient safety. & 0.45 \\
\hline $\begin{array}{l}\text { The manager or head nurse supports me in the event of a conflict } \\
\text { between me and a patient. }\end{array}$ & -0.38 \\
\hline Primary caregivers do not execute their tasks appropriately. & 0.38 \\
\hline \multicolumn{2}{|l|}{ 10. Unmet Basic Physiological Needs } \\
\hline I have no time to fulfill my personal needs (e.g., water consumption and toilet breaks). & 0.61 \\
\hline I cannot take an uninterrupted 30-minute mealtime break. & 0.80 \\
\hline $\begin{array}{l}\text { I can receive deserved compensation such as premiums and compensatory leave for } \\
\text { overtime of more than } 1 \mathrm{~h} \text {. }\end{array}$ & -0.47 \\
\hline
\end{tabular}

Note: Factor loadings of $>0.32$ are recognized on the subscale. ${ }^{a}$ SARS: severe acute respiratory syndrome; AIDS: acquired immune deficiency syndrome. ${ }^{b}$ Transfer of percentages to scores are explained as follows: $0 \%-25 \%=4$, $26 \%-50 \%=3,51 \%-75 \%=2,76 \%-100 \%=1$. Items not classified under any factors in the table: "I cannot complete my duties or required tasks during working hours" and "In the preceding month, I have used free time to handle documents from the hospital for accreditation or unit-related affairs". hour(s) of my

\subsubsection{Test-Retest Reliability}

A convenience sample of 50 hospital nurses from northern, central, and southern Taiwan was invited to assess test-retest reliability; 36 pairs of test-retest questionnaires were completed. Test-retest reliability scores were calculated through Pearson's correlation with a 2-week interval. The Pearson's correlation coefficients of the 10 subscales were $0.75,0.72,0.74,0.75,0.72,0.75,0.71,0.76,0.72$, and 0.61 . The test-retest reliability of the whole NOSS was 0.84 . 


\subsubsection{Internal Consistency Reliability}

Most NOSS items were scored on a 4-point Likert scale (1 to 4 representing "strongly disagree" to "strongly agree"), whereas 5 items were reverse scored. The average total score of the NOSS was 107.1 $(\mathrm{SD}=14.2)$, ranging from 65 to 158. A higher score indicated a higher frequency of work stressors experienced by the participant in question. Cronbach's $\alpha$ was used to measure the internal consistency. The internal consistency scores of the 10 NOSS subscales were $0.88,0.92,0.87,0.86,0.35,0.63,0.86,0.78$, 0.06 , and 0.63 . The internal consistency of the whole NOSS was 0.89 .

\subsection{Phase 2: Condensation of the NOSS According to Validity and Reproducibility}

The initial NOSS underwent a condensation process to reduce item numbers. All items on the condensed NOSS were selected from the original NOSS. Items were examined as independent variables, and personal burnout, client-related burnout, job dissatisfaction, and intention to leave were set as dependent variables. The selection algorithms were based on predictions of dependent variables and reliability. Items with favorable prediction were prioritized for inclusion in the condensed scale and those without favorable prediction or low reliability were re-examined through panel discussions.

First, common factor analysis of the 43 items selected for the condensed scale yielded 10 factors (Table 2): "work demands", "work-family conflict", "insufficient support from coworkers or caregivers", "workplace violence and bullying", "organizational issues", "occupational hazards", "difficulty taking leave", "powerlessness", "interpersonal relationships", and "unmet basic physiological needs". Since the item numbers differed among factors, the total score of each factor was adjusted to between 0 and 100. Table 3 presents the areas under the receiver operating characteristic curves (AUCs) used to examine sensitivity and specificity. Forward stepwise with a $p$ value of 0.1 was implemented to examine predictions of indicators under each of the 10 factors. Factors 1, 2, 4, 6, and 7 were significantly related to personal burnout (AUC $=0.79$ ). Factors $1,2,3,4,7$, and 8 were significantly related to client-related burnout (AUC $=0.80$ ). Factors 1, 2, 6, 7, and 10 were significantly related to job dissatisfaction (AUC $=0.75$ ). Factors 1, 2, 4, 5, 7, and 10 were significantly related to intention to leave $(\mathrm{AUC}=0.75)$. Factor 9 -interpersonal relationships-was not significantly related to any indicators.

Table 3. Personal burnout, client-related burnout, job dissatisfaction, and intention to leave as indicators for item retention on the NOSS $(\mathrm{N}=1781)$.

\begin{tabular}{|c|c|c|c|c|c|c|c|c|}
\hline \multirow[t]{2}{*}{ Factor } & \multicolumn{2}{|c|}{ Personal Burnout ${ }^{a}$} & \multicolumn{2}{|c|}{$\begin{array}{l}\text { Client-Related } \\
\text { Burnout }^{b}\end{array}$} & \multicolumn{2}{|c|}{ Job Dissatisfaction $^{c}$} & \multicolumn{2}{|c|}{ Intention to Leave ${ }^{d}$} \\
\hline & OR & AUC & OR & AUC & OR & AUC & OR & AUC \\
\hline 1 & $1.04^{* * *}$ & 0.68 & $1.05^{* * *}$ & 0.73 & $1.06^{* * *}$ & 0.77 & $1.06^{* * *}$ & 0.78 \\
\hline 2 & $1.04^{* * *}$ & 0.68 & $1.06^{* * *}$ & 0.75 & $1.04^{* * *}$ & 0.69 & $1.04^{* * *}$ & 0.67 \\
\hline 3 & $1.03^{* * *}$ & 0.64 & $1.04^{* * *}$ & 0.70 & $1.05^{* * *}$ & 0.71 & $1.05^{* * *}$ & 0.73 \\
\hline 5 & 1.02 *** & 0.64 & $1.02^{* * * *}$ & 0.64 & $1.02^{* * *}$ & 0.63 & $1.02 * * *$ & 0.63 \\
\hline 6 & 1.02 *** & 0.60 & $1.03^{* * *}$ & 0.69 & $1.03^{* * *}$ & 0.67 & $1.03^{* * *}$ & 0.68 \\
\hline 7 & $1.02^{* * *}$ & 0.66 & $1.01^{* * *}$ & 0.62 & $1.01^{* * *}$ & 0.63 & $1.01^{* * *}$ & 0.61 \\
\hline 8 & $1.02^{* * *}$ & 0.59 & $1.03^{* * *}$ & 0.64 & $1.02^{* * *}$ & 0.61 & $1.02 * * *$ & 0.62 \\
\hline 9 & $1.02 * * *$ & 0.63 & $1.04^{* * *}$ & 0.69 & $1.04^{* * *}$ & 0.68 & $1.04^{* * *}$ & 0.70 \\
\hline
\end{tabular}

Note: OR: odds ratio; AUC: areas under the receiver operating characteristic curves. ${ }^{*} p<0.05,{ }^{* * *} p<0.001$.

a The standardized total score for personal burnout was $\geq 65 .{ }^{\mathrm{b}}$ The standardized total score for client-related burnout was $\geq 95$. " "Somewhat unsatisfied" and "Quite unsatisfied" were classified as job dissatisfaction. ${ }^{\mathrm{d}}$ Intention to leave was defined as "unlikely to or uncertain about staying in the job for another two years", "score on the scale of leaving the job $\geq 7$ ", and "thinking about leaving once in a month or more frequently".

The stability of the NOSS was assessed through evaluation of test-retest reliability. The values of the 10 factors ranged from 0.61 to 0.76 . After setting the minimum stability value of 0.70 [29], factor 10 -with a stability value of 0.61 -was revised. 
A range of $0.3-0.7$ was set for internal consistency reliability by recommendation [30]. The internal consistency reliability of the NOSS factors ranged from 0.35 to 0.92 , except for factor $9(0.06)$. Prominent items were preserved to represent the concept of each factor. Because of the conceptual similarity between factor 9 (interpersonal relationships) and factor 3 (insufficient support from coworkers or caregivers), two items of factor 9 ("I am worried that the incompetence of my colleagues will affect patient safety" and "The primary caregivers do not execute their tasks appropriately") were reclassified under factor 3 and all other items under factor 9 were omitted.

\subsection{Phase 3: Examination of Accuracy of the Condensed NOSS for Predicting Stress Outcomes}

\subsubsection{Phase 3 Questionnaire Survey}

After revision, the participants for the confirmation survey were sampled from 417 hospitals in 2014. A total of 71 candidate hospitals (1 tertiary, 7 secondary, and 63 primary hospitals) were sampled. A total of 3974 nurses were recruited, and 3786 returned the questionnaires. Under the same exclusion criteria as those of the 2013 survey, 2655 questionnaires were deemed eligible for analysis, yielding an effective response rate of $66.8 \%$. The participants' demographic characteristics are shown in Table 1.

\subsubsection{Test-Retest Reliability of the 21-Item Condensed NOSS}

Of 50 nurses who worked in primary, secondary, and tertiary hospitals in Taiwan, 48 completed the test-retest study within one week. According to Pearson's correlation, the $\mathrm{p}$ values of the nine factors ranged from 0.71 to 0.83 . The test-retest reliability of the overall 21-item NOSS was 0.76 .

\subsubsection{Internal Consistency Reliability of the 21-Item Condensed NOSS}

Table ?? presents the item-to-subscale correlations. The Cronbach's $\alpha$ scores of the subscales ranged from 0.35 to 0.77 except for "workplace violence and bullying", which contained only one item, and thus lacked internal consistency reliability. The internal consistency of the 21-item NOSS as a whole was 0.91 .

Table 4. Statistics of the 21-item NOSS $(N=2655)$.

\begin{tabular}{|c|c|c|c|c|}
\hline & Item & Mean & SD & $\begin{array}{l}\text { Cronbach's } \alpha \text { if the } \\
\text { Item is Deleted }\end{array}$ \\
\hline \multicolumn{2}{|r|}{$\begin{array}{l}\text { Subscale 1: Work Demands } \\
\quad \text { (Cronbach's } \alpha: 0.61 \text { ) }\end{array}$} & & & \\
\hline 1 & I have to bear negative sentiment from patients or their relatives. & 3.16 & 0.66 & 0.44 \\
\hline 2 & Excessive duties in the workplace prevent me from attending to patients. & 3.01 & 0.73 & 0.58 \\
\hline \multicolumn{2}{|r|}{$\begin{array}{l}\text { Subscale 2: Work-Family Conflict } \\
\text { (Cronbach's } \alpha: 0.70)\end{array}$} & & & \\
\hline 4 & The burden of work affects my domestic life. & 2.89 & 0.69 & 0.79 \\
\hline 5 & $\begin{array}{l}\text { The burden of work makes it difficult for me to undertake my personal } \\
\text { chores and/or engage in hobbies. }\end{array}$ & 2.82 & 0.73 & 0.53 \\
\hline 7 & Doctors' temperamental nature agitates me. & 3.14 & 0.69 & 0.48 \\
\hline 8 & I worry that my colleagues' incompetence will affect patient safety. & 2.85 & 0.68 & 0.56 \\
\hline 9 & $\begin{array}{l}\text { I feel stressed because primary caregivers do not execute their } \\
\text { tasks appropriately. }\end{array}$ & 2.96 & 0.65 & 0.53 \\
\hline \multicolumn{2}{|r|}{ Subscale 4: Workplace Violence and Bullying } & & & \\
\hline 10 & $\begin{array}{l}\text { I feel stressed due to psychological abuse such as threats, discrimination, } \\
\text { bullying, and harassment. }\end{array}$ & 2.85 & 0.76 & - \\
\hline
\end{tabular}




\begin{tabular}{|c|c|c|c|c|}
\hline & Item & Mean & SD & $\begin{array}{l}\text { Cronbach's } \alpha \text { if the } \\
\text { Item is Deleted }\end{array}$ \\
\hline \multicolumn{5}{|c|}{$\begin{array}{l}\text { Subscale 5: Organizational Issues } \\
\quad(\text { Cronbach's } \alpha: 0.59)\end{array}$} \\
\hline 11 & The on-call system affects my life. & 2.97 & 0.82 & 0.45 \\
\hline 12 & $\begin{array}{l}\text { The organization usually remunerates my overtime work at a low } \\
\text { rate of pay. }\end{array}$ & 2.77 & 0.81 & 0.47 \\
\hline 13 & $\begin{array}{l}\text { Not achieving a promotion (e.g., level } 1 \text { or } 2 \text { ) within the expected period } \\
\text { affects my income. }\end{array}$ & 3.04 & 0.76 & 0.55 \\
\hline \multicolumn{5}{|c|}{$\begin{array}{l}\text { Subscale 6: Occupational Hazards } \\
\quad \text { (Cronbach's } \alpha: 0.39)\end{array}$} \\
\hline 14 & $\begin{array}{l}\text { I feel stressed considering that my patients might be have contagious } \\
\text { diseases such as SARS or AIDS. }\end{array}$ & 3.21 & 0.65 & - \\
\hline 15 & I need to transport patients or equipment. & 3.12 & 0.76 & - \\
\hline \multicolumn{5}{|c|}{$\begin{array}{l}\text { Subscale 7: Difficulty Taking Leave } \\
\quad \text { (Cronbach's } \alpha: 0.77 \text { ) }\end{array}$} \\
\hline 16 & I cannot ask for leaves for household emergencies. & 2.87 & 0.83 & - \\
\hline 17 & I cannot excuse myself for feeling strong discomfort. & 2.60 & 0.84 & - \\
\hline \multicolumn{5}{|c|}{$\begin{array}{l}\text { Subscale 8: Powerlessness } \\
\quad \text { (Cronbach's } \alpha: 0.35)\end{array}$} \\
\hline 18 & It upsets me if patients' conditions do not improve. & 2.77 & 0.65 & - \\
\hline 19 & $\begin{array}{l}\text { I have insufficient time to offer mental health care to patients during } \\
\text { working hours. }\end{array}$ & 3.00 & 0.67 & - \\
\hline \multicolumn{5}{|c|}{$\begin{array}{l}\text { Subscale 9: Unmet Basic Physiological Needs } \\
\text { (Cronbach's } \alpha: 0.69 \text { ) }\end{array}$} \\
\hline 20 & $\begin{array}{l}\text { I have no time to fulfill my personal needs (e.g., water consumption and } \\
\text { toilet breaks). }\end{array}$ & 2.81 & 0.75 & - \\
\hline 21 & I cannot take an uninterrupted 30-minute mealtime break. & 3.02 & 0.81 & - \\
\hline
\end{tabular}

\subsubsection{Comparison of the prediction accuracy of the original NOSS and condensed NOSS}

To examine predictions of intermediate markers by the original and condensed NOSSs, the two scales were compared with respect to personal burnout, client-related burnout, job dissatisfaction, and intention to leave (Table 5). The AUCs for the indicators ranged from 0.73 to 0.82 on the condensed NOSS. Among the participants of the first year survey, the AUCs for the original 43-question version ranged from 0.75 to 0.80 and those for the condensed version ranged from 0.75 to 0.81 . These results suggested that the condensed NOSS might be equally sensitive and specific to the original NOSS for predicting nurses' stress outcomes.

Table 5. Revision and confirmation of the NOSS.

\begin{tabular}{|c|c|c|c|c|c|c|c|c|c|c|c|c|}
\hline \multirow{2}{*}{ Variable } & \multicolumn{3}{|c|}{ Personal Burnout } & \multicolumn{3}{|c|}{ Client-Related Burnout } & \multicolumn{3}{|c|}{ Job Dissatisfaction } & \multicolumn{3}{|c|}{ Intention to Leave } \\
\hline & Factors & AUC & $\mathbf{R}^{2}$ & Factors & AUC & $\mathbf{R}^{2}$ & Factors & AUC & $\mathbf{R}^{2}$ & Factors & AUC & $\mathbf{R}^{2}$ \\
\hline $\begin{array}{c}\text { 43-item } \\
\text { NOSS } \\
\text { in 1st year }(N=1781)\end{array}$ & $\begin{array}{l}1 \\
2 \\
4 \\
6 \\
7\end{array}$ & 0.79 & $18.81 \%$ & $\begin{array}{l}1 \\
2 \\
3 \\
4 \\
7 \\
8\end{array}$ & 0.80 & $18.52 \%$ & $\begin{array}{c}1 \\
2 \\
6 \\
7 \\
10\end{array}$ & 0.75 & $14.41 \%$ & $\begin{array}{c}1 \\
2 \\
4 \\
5 \\
7 \\
10\end{array}$ & 0.75 & $12.16 \%$ \\
\hline $\begin{array}{c}\text { 21-item } \\
\text { NOSS } \\
\text { in 1st year }(N=1781)\end{array}$ & $\begin{array}{l}4 \\
6 \\
7\end{array}$ & 0.81 & $19.93 \%$ & $\begin{array}{l}3 \\
4 \\
7 \\
8\end{array}$ & 0.79 & $19.13 \%$ & $\begin{array}{c}6 \\
7 \\
9^{\mathrm{a}}\end{array}$ & 0.76 & $14.73 \%$ & $\begin{array}{c}4 \\
5 \\
7 \\
9 \\
9\end{array}$ & 0.75 & $12.87 \%$ \\
\hline
\end{tabular}

${ }^{\text {a }}$ What was originally factor 9 was deleted and factor 10 became the new factor 9 in the 21-item NOSS.

The process of the NOSS development is illustrated in Figure 1. 


\begin{tabular}{|c|c|}
\hline \multicolumn{2}{|c|}{ Phase 1: Generation and pilot testing of candidate questions } \\
\hline $\begin{array}{l}\text { Identification of candidate } \\
\text { questions }\end{array}$ & $\begin{array}{l}\text { - Literature review } \\
\text { - Focus group } \\
\text { - Questionnaire design } \\
\text { - Expert feedback } \\
\text { - Pretest }(\mathrm{N}=36)\end{array}$ \\
\hline Questionnaire survey in 2013 & $\begin{array}{l}\text { - Participants: } 2956 \\
\text { - Returned questionnaires: } 2796 \\
\text { - Removed invalid questionnaires: } 1015 \\
\text { - Effective response rate: } 60.3 \%(\mathrm{~N}=1781)\end{array}$ \\
\hline \multicolumn{2}{|c|}{ Phase 2: Condensation of the scale according to validity and reproducibility } \\
\hline & $\begin{array}{l}\text { - Original: } 45 \text { items, } 43 \text { of which could be classified under } \\
10 \text { factors } \\
\text { - Retained AUCs of indicators of } \geq 0.7 \text {; representative } \\
\text { items: } 21 \text { items with } 9 \text { factors }\end{array}$ \\
\hline \multicolumn{2}{|c|}{ Phase 3: Examination of accuracy of the condensed NOSS for predicting stress outcomes } \\
\hline Questionnaire survey in 2014 & $\begin{array}{l}\text { - Participants: } 3974 \\
\text { - Returned questionnaires: } 3786 \\
\text { - Removed invalid questionnaires: } 1131 \\
\text { - Effective response rate: } 66.8 \%(\mathrm{~N}=2655)\end{array}$ \\
\hline
\end{tabular}

Figure 1. The process of the NOSS development.

\section{Discussion}

This study constituted the effort to develop a stressor scale for nurses in Asia.Despite measurements for stress reactions being used extensively, workplace factors, namely stressors among hospital nurses, are rarely characterized or quantified. The ENSS contains 57 items and was tested on 2280 randomly selected nurses; the scale was found to be correlated with overall life stress items and health problem indices [21]. The NOSS has three major advantages: (1) comprehensive assessment of nursing work traits that could interfere with life, including occupational hazards, workplace violence and bullying, difficulty taking leave, and unmet basic physiological needs; (2) 21 items only, so relatively little time required for completion; and (3) comparisons with four important stress indicators in both surveys and reasonable prediction of these outcomes.

This section discusses the results of using factors of the NOSS and indicators for confirmation. Burnout is regarded as a response to job stressors correlated with excessive direct contact with patients [3,31]. Hence, "work demands", "insufficient support from coworkers or caregivers", and "workplace violence and bullying" [6,12] may be reasonable factors for predicting personal burnout and client-related burnout. Work-life conflict was regarded as a strong predictor of burnout $[32,33]$. Consequently, the relationship between "work-family conflict" and burnout is predictable. According to the World Health Organization [34], ergonomic hazards is one of potential health hazards among health care workers. Studies conducted in Hong Kong and Japan have revealed that manually lifting patients or heavy objects is a risk factor associated with musculoskeletal disorders such as lower back pain $[35,36]$. Other researchers observed that lower back pain was related to personal burnout [37]. Thus, it seems plausible that "occupational hazards" factor is associated with personal burnout. Taking a sick leave or a leave for family-related reasons is not easy for Japanese nurses; without substitutes, other nurses need to work harder or more hours to compensate. Thus, nurses may feel guilty about taking leaves, and inability to take leaves could lead to burnout or even overwork death [38]. The "difficulty taking leave" factor may reliably predict burnout. Items under the "powerlessness" factor have been verified as being associated with client-related burnout. Due to higher frequency of suffering patients contact, 
nurses might experience greater compassion fatigue than other professionals [3]. Burnout can easily occur among those caring for dying people [39], and the associated feeling of powerless and the inability to deliver effective care to such people could cause moral dilemmas and burnout [40].

Researchers observed a negative relationship between job satisfaction and nursing tasks left undone [41]. Furthermore, nursing care may be forced out of a work schedule by non-nursing tasks, and neglected nursing care was found to be a strong predictor of intention to leave [42]. These findings may match the relationships of the "work demands" factor with job dissatisfaction and intention to leave in the study.

Confrontations with patients and their families may be another nursing stressor [43]; however, the relationships of this item with job dissatisfaction and intention to leave were nonsignificant. A study among physicians revealed that job satisfaction decreased and intention to leave increased when "work-family conflict" increased [44]. Besides, nurses were dissatisfied with inadequate protective equipment when caring for highly infectious patients [45]. This may support our finding of a relationship between "occupational hazards" and job dissatisfaction. In a meta-analysis [46], availability and use of work-family support policies positively related to job satisfaction and intention to stay. In short, the "difficulty taking leave" factor may reliably predict burnout, job dissatisfaction, and intention to leave. For decades, nurses' meal breaks and rest breaks have been regarded as a factor possibly related to job satisfaction and intention to stay [47]. Instances of nurses holding their urine or decreasing their water consumption were recorded [48]. Accordingly, the items categorized under the "unmet basic physiological needs" factor may be common in Taiwan and China.

One item on the NOSS is rather culturally unique; despite patients' family members not being intuitively recognized as having such collegial relationships as those that nurses have with patients, family members have long made commitments to care for hospitalized patients because of the Chinese value of filial piety [49]. Because hospitals reduce nursing manpower to minimize costs, a portion of care depends on family members or private attendants. Therefore, unsurprisingly, "feeling stressed because primary caregivers do not execute their tasks appropriately" predicts client-related burnout.

"I have to maintain professional units other than my own" was found to be related to personal burnout, client-related burnout, job dissatisfaction, and intention to leave. These outcomes were observed when nursing units had temporary shortages of personnel. However, one would imagine the nurses who worked in another unit could face unfamiliar medical equipment, coworkers and an unfamiliar environment. These likely induce additional stress.

This study had some limitations. First, males were excluded. The distribution of male nurse in our study was $2.4 \%(n=46)$ and that in Taiwan was approximately $1.6 \%$ at the time of the study [13]. Because the exclusion of male nurses had no impact on the results (data not shown), only female nurses were analyzed. Second, questionnaires with any missing item were excluded to ensure the accuracy of developing NOSS, which was the major reason of effective response rates less than $70 \%$. There was not significant different of participants' demographics between valid and invalid questionnaires (data not shown). Third, the NOSS was developed for hospital nurses; thus, the scale might not be applicable to clinics or nursing homes. Fourth, nurses unable to adapt to given work environments, had left the profession, or had transferred to less stressful environments were not included. Therefore, a healthy worker effect or healthy worker survival effect [50] may be present, and this could have led to underestimation of stress in the study. Fifth, although a single factor is suggested to include at least three items [51], we decided not to ignore less items to detect nursing stressors due to uniqueness of nursing clinical environment. Accordingly, factor 4 had only one item and factor 6 , factor 7 , factor 8 , and factor 9 had only two items. The AUCs of the first- and second-year observations revealed that the 21-item NOSS may be adequate for predicting indicators of common stress among nurses. Finally, our questionnaire did not contain items about participant's income, economic burden or job insecurity. As described in previous studies, global economic crisis could have caused hospital budgets reduction, and consequently led to medical supply shortage, increased workload and job insecurity $[52,53]$. Thus, economic crisis was regarded as an important stressor related to workers' 
mental health status [52]. Further studies may consider financial factors while assess nursing practice environment and related outcomes.

The strengths of the study are described as follows. First, this study analyzed a nationally representative sample based on stratified sampling. Second, in both surveys, rather large numbers of nurses completed the questionnaire, enabling examination of factors and their relationships with stress indicators. Third, the identified stressors in this study were individually related to the subscales of burnout, job dissatisfaction, and intention to leave. The identified stressors can be applied in other countries if pretesting for comparisons with stress indicators is conducted.

\section{Conclusions}

This current study developed NOSS, which identified nine groups of occupational stressors in nursing practice environments, as well as predicting personal burnout, client-related burnout, job dissatisfaction, and intention to leave. Using this scale, stressors in nurses' work environment can be measured, and while intervention is applied, the effectiveness of such intervention can be evaluated.

Author Contributions: Conceptualization, J.-J.H. and J.S.-C.S.; data curation, Y.-C.C. and J.S.-C.S.; formal analysis, Y.-C.C., Y.-L.L.G., Y.-J.L. and J.S.-C.S.; funding acquisition, J.-J.H.; investigation, Y.-C.C. and Y.-J.L.; methodology, L.-C.L., Y.-L.L.G. and J.S.-C.S.; project administration, P.-Y.H. and J.S.-C.S.; resources, P.-Y.H.; supervision, J.-J.H. and J.S.-C.S.; validation, L.-C.L. and Y.-L.L.G.; visualization, Y.-C.C.; writing-original draft, Y.-C.C., Y.-L.L.G. and J.S.-C.S.; writing-review and editing, Y.-C.C., Y.-L.L.G., L.-C.L., Y.-J.L., P.-Y.H., J.-J.H. and J.S.-C.S. All authors have read and agreed to the published version of the manuscript.

Funding: This research was supported by the Institute of Labor, Occupational Safety and Health, Ministry of Labor, Taiwan. Grant number: ILOSH 103-R328 and ILOSH 104-A315.

Acknowledgments: We thank Wei-Shan Chin for statistical recommendations. We are grateful to the volunteer participants, and appreciate the financial support from the Institute of Labor, Occupational Safety and Health, Ministry of Labor, Taiwan.

Conflicts of Interest: The authors declare no conflicts of interest.

\section{References}

1. International Labour Organization. Occupational Stress and Stress Prevention in Specific Occupations. Available online: https:/www.ilo.org/safework/areasofwork/workplace-health-promotion-and-well-being/ WCMS_250122/lang--en/index.htm (accessed on 3 January 2020).

2. Bobbio, A.; Manganelli, A.M. Antecedents of hospital nurses' intention to leave the organization: A cross sectional survey. Int. J. Nurs. Stud. 2015, 52, 1180-1192. [CrossRef]

3. Wang, J.; Okoli, C.T.C.; He, H.; Feng, F.; Li, J.; Zhuang, L.; Lin, M. Factors associated with compassion satisfaction, burnout, and secondary traumatic stress among Chinese nurses in tertiary hospitals: A cross-sectional study. Int. J. Nurs. Stud. 2020, 102, 103472. [CrossRef]

4. Kupcewicz, E.; Jóźwik, M. Positive orientation and strategies for coping with stress as predictors of professional burnout among Polish nurses. Int. J. Environ. Res. Public Health 2019, 16, 4264. [CrossRef]

5. Khamisa, N.; Peltzer, K.; Ilic, D.; Oldenburg, B. Work related stress, burnout, job satisfaction and general health of nurses: A follow-up study. Int. J. Nurs. Pract. 2016, 22, 538-545. [CrossRef] [PubMed]

6. Giorgi, G.; Mancuso, S.; Fiz Perez, F.; Castiello D'Antonio, A.; Mucci, N.; Cupelli, V.; Arcangeli, G. Bullying among nurses and its relationship with burnout and organizational climate. Int. J. Nurs. Pract. 2016, 22, 160-168. [CrossRef] [PubMed]

7. Chin, W.S.; Chen, Y.C.; Ho, J.J.; Cheng, N.Y.; Wu, H.C.; Shiao, J.S.C. Psychological work environment and suicidal ideation among nurses in Taiwan. J. Nurs. Scholarsh. 2019, 51, 106-113. [CrossRef]

8. Aiken, L.H.; Clarke, S.P.; Sloane, D.M.; Sochalski, J.; Silber, J.H. Hospital nurse staffing and patient mortality, nurse burnout, and job dissatisfaction. JAMA 2002, 288, 1987-1993. [CrossRef]

9. Petit Dit Dariel, O.; Regnaux, J.P. Do Magnet ${ }^{\circledR}$-accredited hospitals show improvements in nurse and patient outcomes compared to non-Magnet hospitals: A systematic review. JBI Database Syst. Rev. Implement. Rep. 2015, 13, 168-219. [CrossRef]

10. Ying, L.; Aungsuroch, Y. Factors influencing nurse-assessed quality nursing care: A cross-sectional study in hospitals. J. Adv. Nurs. 2018, 74, 935-945. 
11. Chin, W.; Guo, Y.L.; Hung, Y.J.; Hsieh, Y.T.; Wang, L.J.; Shiao, J.S. Workplace justice and intention to leave the nursing profession. Nurs. Ethics 2019, 26, 307-319. [CrossRef]

12. Liu, W.; Zhao, S.; Shi, L.; Zhang, Z.; Liu, X.; Li, L.; Duan, X.; Li, G.; Lou, F.; Jia, X.; et al. Workplace violence, job satisfaction, burnout, perceived organisational support and their effects on turnover intention among Chinese nurses in tertiary hospitals: A cross-sectional study. BMJ Open 2018, 8, e019525. [CrossRef] [PubMed]

13. Taiwan Union of Nurses Association (TUNA). Statistics of Nurses in Taiwan and Fujian Provinces: From 2013 to 2019. (In Chinese). Available online: http://www.nurse.org.tw/publicUI/H/H102.aspx (accessed on 3 January 2020).

14. Ministry of Health, Singapore. Health Manpower. Available online: https://www.moh.gov.sg/content/moh_ web/home/statistics/Health_Facts_Singapore/Health_Manpower.html (accessed on 3 January 2020).

15. Nursing and Midwifery Board of Australia. NMBA Quarterly Registration Data. Available online: http: //www.nursingmidwiferyboard.gov.au/News/Newsletters/September-2015.aspx\#quarterlydata (accessed on 3 January 2020).

16. Taiwan Union of Nurses Association (TUNA). The survey of the nursing workforce. TUNA Nurs. Newsl. 2010, 76, 2-3. (In Chinese)

17. Leineweber, C.; Chungkham, H.S.; Lindqvist, R.; Westerlund, H.; Runesdotter, S.; Smeds Alenius, L.; Tishelman, C. Nurses' practice environment and satisfaction with schedule flexibility is related to intention to leave due to dissatisfaction: A multi-country, multilevel study. Int. J. Nurs. Stud. 2016, 58, 47-58. [CrossRef] [PubMed]

18. Aqeel Alkhawaldeh, J.F.M.; Soh, K.L.; Mukhtar, F.B.M.; Ooi, C.P. Effectiveness of stress management interventional program on occupational stress for nurses: A systematic review. J. Nurs. Manag. 2019. [CrossRef] [PubMed]

19. Happell, B.; Dwyer, T.; Reid-Searl, K.; Burke, K.J.; Caperchione, C.M.; Gaskin, C.J. Nurses and stress: Recognizing causes and seeking solutions. J. Nurs. Manag. 2013, 21, 638-647. [CrossRef]

20. Rainbow, J.G.; Steege, L.M. Transition to practice experiences of first- and second-career nurses: A mixed-methods study. J. Clin. Nurs. 2019, 28, 1193-1204. [CrossRef]

21. French, S.E.; Lenton, R.; Walters, V.; Eyles, J. An empirical evaluation of an expanded Nursing Stress Scale. J. Nurs. Manag. 2000, 8, 161-178. [CrossRef]

22. Lake, E.T. Development of the practice environment scale of the Nursing Work Index. Res. Nurs. Health 2002, 25, 176-188. [CrossRef]

23. Yeh, W.Y.; Cheng, Y.W.; Chen, M.J.; Chiu, A.W.H. Development and validation of an occupational burnout inventory. Taiwan J. Public Health 2008, 27, 349-364.

24. Chin, W.; Guo, Y.L.; Hung, Y.J.; Yang, C.Y.; Shiao, J.S. Short sleep duration is dose-dependently related to job strain and burnout in nurses: A cross sectional survey. Int. J. Nurs. Stud. 2015, 52, 297-306. [CrossRef]

25. Kaiser, H.F. An index of factorial simplicity. Psychometrika 1974, 39, 31-36. [CrossRef]

26. Tobias, S.; Carlson, J.E. Brief report: Bartlett's test of sphericity and chance findings in factor analysis. Multivar. Behav. Res. 1969, 4, 375-377. [CrossRef]

27. Lin, M.H.; Kuo, C.Y. Survey of Perceptions of Safety and Health in the Work Environment in 2013 Taiwan (IOSH102-M306); Institute of Labor, Occupational Safety and Health, Ministry of Labor: New Taipei City, Taiwan, 2014; (In Chinese, English Abstract).

28. Netemeyer, R.G.; Boles, J.S.; McMurrian, R. Development and validation of work-family conflict and family-work conflict scales. J. Appl. Psychol. 1996, 81, 400-410. [CrossRef]

29. Kneebone, I.I.; Dewar, S.J. Reliability and validity of the Attributional Style Questionnaire- Survey in people with multiple sclerosis. Ther. Adv. Neurol. Disord. 2017, 10, 33-40. [CrossRef] [PubMed]

30. Polit, D.F.; Beck, C.T. Developing and testing self-reporting scales. In Nursing Research: Generating and Assessing Evidence for Nursing Practice, 9th ed.; Polit, D.F., Beck, C.T., Eds.; Wolters Kluwer Health/Lippincott Williams \& Wilkins: Philadelphia, PA, USA, 2012; pp. 351-378.

31. Peltzer, K.; Mashego, T.A.; Mabeba, M. Short communication: Occupational stress and burnout among South African medical practitioners. Stress Health 2003, 19, 275-280. [CrossRef]

32. Chen, L.; Liu, J.; Yang, H.; Ma, H.; Wang, H.; Huang, Y.; Cheng, H.; Tang, D.; Liu, M.; Luo, H.; et al. Work-family conflict and job burn-out among Chinese doctors: The mediating role of coping styles. BMJ Open 2018, 31, e00004. [CrossRef] 
33. Brauchli, R.; Bauer, G.F.; Hämmig, O. Relationship between time-based work-life conflict and burnout: A cross-sectional study among employees in four large Swiss enterprises. Swiss J. Psychol. 2011, 70, 165-173. [CrossRef]

34. World Health Organization. Occupational Health: A Manual for Primary Health Care Workers. Available online: https://www.who.int/occupational_health/publications/emhealthcarework/en/ (accessed on 26 December 2019).

35. Yip, Y. A study of work stress, patient handling activities and the risk of low back pain among nurses in Hong Kong. J. Adv. Nurs. 2001, 36, 794-804. [CrossRef]

36. Smith, D.R.; Mihashi, M.; Adachi, Y.; Koga, H.; Ishitake, T. A detailed analysis of musculoskeletal disorder risk factors among Japanese nurses. J. Saf. Res. 2006, 37, 195-200. [CrossRef]

37. Kozak, A.; Schedlbauer, G.; Peters, C.; Nienhaus, A. Self-reported musculoskeletal disorders of the distal upper extremities and the neck in German veterinarians: A cross-sectional study. PLoS ONE 2014, 9, e89362. [CrossRef]

38. Mizuno-Lewis, S.; McAllister, M. Taking leave from work: The impact of culture on Japanese female nurses. J. Clin. Nurs. 2008, 17, 274-281. [CrossRef] [PubMed]

39. Brindley, P.G. Psychological burnout and the intensive care practitioner: A practical and candid review for those who care. J. Intensive Care Soc. 2017, 18, 270-275. [CrossRef] [PubMed]

40. Kilcoyne, M.; Dowling, M. Working in an overcrowded accident and emergency department: Nurses' narratives. Aust. J. Adv. Nurs. 2008, 25, 21-27.

41. Bekker, M.; Coetzee, S.K.; Klopper, H.C.; Ellis, S.M. Non-nursing tasks, nursing tasks left undone and job satisfaction among professional nurses in South African hospitals. J. Nurs. Manag. 2015, 23, 1115-1125. [CrossRef]

42. Tschannen, D.; Kalisch, B.J.; Lee, K.H. Missed nursing care: The impact on intention to leave and turnover. Can. J. Nurs. Res. 2010, 42, 22-39.

43. Hinz, C. How to Deal with Difficult Family Members of Patients. Available online: https://dailynurse.com/ how-to-deal-with-difficult-family-members-of-patients/ (accessed on 26 December 2019).

44. Lu, Y.; Hu, X.M.; Huang, X.L.; Zhuang, X.D.; Guo, P.; Feng, L.F.; Hu, W.; Chen, L.; Zou, H.; Hao, Y.T. The relationship between job satisfaction, work stress, work-family conflict, and turnover intention among physicians in Guangdong, China: A cross-sectional study. BMJ Open 2017, 7, e014894. [CrossRef]

45. Chen, S.L.; Chen, K.L.; Lee, L.H.; Yang, C.I. Working in a danger zone: A qualitative study of Taiwanese nurses' work experiences in a negative pressure isolation ward. Am. J. Infect. Control 2016, 44, 809-814. [CrossRef]

46. Butts, M.M.; Casper, W.J.; Yang, T.S. How important are work-family support policies? A meta-analytic investigation of their effects on employee outcomes. J. Appl. Psychol. 2013, 98, 1-25. [CrossRef]

47. Wendsche, J.; Ghadiri, A.; Bengsch, A.; Wegge, J. Antecedents and outcomes of nurses' rest break organization: A scoping review. Int. J. Nurs. Stud. 2017, 75, 65-80. [CrossRef]

48. Xu, D.; Chen, L.; Wan, X.; Zhang, Y.; Liu, N.; Wang, K. Toileting behaviour and related health beliefs among Chinese female nurses. Int. J. Clin. Pract. 2016, 70, 416-423. [CrossRef]

49. Chao, S.Y.; Roth, P. The experiences of Taiwanese women caring for parents-in-law. J. Adv. Nurs. 2000, 31, 631-638. [CrossRef] [PubMed]

50. Rothman, K.J.; Greenland, S.; Lash, T.L. (Eds.) Validity in Epidemiologic Studies. In Modern Epidemiology, 3rd ed.; Lippincott Williams \& Wilkins: Philadelphia, PA, USA, 2008; pp. 129-146.

51. Carpenter, S. Ten steps in scale development and reporting: A guide for researchers. Commun. Methods Meas. 2018, 12, 25-44. [CrossRef]

52. Mucci, N.; Giorgi, G.; Roncaioli, M.; Fiz Perez, J.; Arcangeli, G.; Mucci, N. The correlation between stress and economic crisis: A systematic review. Neuropsychiatr. Dis. Treat. 2016, 12, 983-993. [CrossRef] [PubMed]

53. Charos, D.; Kolypera, V.; Lazaridou, E.; Andriopoulou, M.; Vivilaki, V.; Livanis, E. The impact of occupational stress on health care professionals during the financial crisis. Arch. Hell. Med. 2017, 34, 467-475.

(C) 2020 by the authors. Licensee MDPI, Basel, Switzerland. This article is an open access article distributed under the terms and conditions of the Creative Commons Attribution (CC BY) license (http://creativecommons.org/licenses/by/4.0/). 